\title{
The Study of the Reaction of Pectin-Ag(0) Nanocomposites Formation
}

\author{
Nadezhda Viktorovna Ivanova, Natalya Nikolaevna Trofimova, \\ Lydmila Alexandrovna Es'kova, and Vasilyi Anatolievich Babkin
}

A.E. Favorsky Institute of Chemistry, Russian Academy of Sciences, Siberian Branch, Irkutsk 664033, Russia

Correspondence should be addressed to Natalya Nikolaevna Trofimova, natrof@inbox.ru

Received 31 May 2012; Accepted 10 October 2012

Academic Editor: Yuriy A. Knirel

Copyright ( 2012 Nadezhda Viktorovna Ivanova et al. This is an open access article distributed under the Creative Commons Attribution License, which permits unrestricted use, distribution, and reproduction in any medium, provided the original work is properly cited.

Pectin polysaccharides (PSs) were isolated from a bark of Larix sibirica Ledeb. Structure of PS fragments determined by chemical transformations, chromatography, and spectroscopic analyses was found to be a linear galacturonane comprising 1,4-linked $\alpha$ $\mathrm{D}-\mathrm{Gal}_{\mathrm{p}} \mathrm{A}$ residues and a rhamnogalacturonan I (RG-I). The fifth part of galacturonane residues was methyl esterified at at C-2 and/or C-3 and C-6 atoms. Some of RG-I side chains were identified as arabinogalactan subunits with highly branched structure consisting of linear backbone with $\rightarrow 3,6)-\beta-\mathrm{D}-\mathrm{Gal}_{\mathrm{p}}-(1 \rightarrow$ residues, substituted at C- 6 by neutral side chains. This side chains contained $\rightarrow 2,5)-\alpha$-L-Ara $-(1 \rightarrow$ and $\rightarrow 3,5)-\alpha$-L-Ara $-(1 \rightarrow$ residues and terminal arabinose in the pyranose and furanose form. It was found that "pectin- $\operatorname{Ag}(0)$ " nanobiocomposites were formed via the interaction between PS aqueous solutions and silver nitrate, with PS playing both reducing and stabilizing functions. It was shown that the content of $\operatorname{Ag}(0)$ particles in "pectin-Ag( $(0)$ " depended on the reaction conditions and can range from 0.1 to $72 \%$, the size of $\mathrm{Ag}(0)$ particles being $3-27 \mathrm{~nm}$. Using ${ }^{13} \mathrm{C} \mathrm{NMR}$ technique, it was revealed that PS underwent destructive changes and they they were more considerable, more than the lot of $\mathrm{Ag}(\mathrm{I})$ that was inputed into the reactionary medium.

\section{Introduction}

Two species of the genus Larix Mill, Larix sibirica Ledeb and Larix gmelinii (Rupr.) Rupr., are considered to be the most abundant trees in the Russian Federation and the total stock of their wood recourses exceeds 26 billion $\mathrm{m}^{3}$. Traditionally, the main economic benefit of the larch wood is a manufacture of roundwood (timber), the value of which is determined by a high quality of lumber obtained from this tree. Sometimes, the larch wood can be used in insignificant quantities in pulp-and-paper manufacture to produce pulp. Currently, about $40 \%$ of this valuable wood (bark, sawdust) is utilized as wastes. Such inexpedient approach to the utilization of larch wood does not allow using the richest potential of this renewable raw material. Meanwhile, biologically active compounds contained in larch biomass can be successfully applied for the manufacture of medical, food, and agricultural products. The development of complex technologies for chemical processing of larch biomass and waste timber will considerably raise the economic value of this biological resource.

However, the larch bark does not find industrial application. Annual volume of waste produced by wood-processing industry and the pulp-and-paper enterprises is more than 30 million $\mathrm{m}^{3}$. It represents a serious environmental challenge because the bark is poorly exposed to biodegradation. At the same time, the chemical compounds of the bark can be used as a source of valuable biologically active substances including polysaccharides.

Earlier we have showed that the content of pectin polysaccharides in the larch bark is about $12 \%$ from the weight of absolutely dry raw material (a.d.r.m.) and the larch bark can be promising alternative raw material. The method of pectin isolation has been developed, and common physical and chemical characteristics and membranotropic activity of pectin have been investigated. 


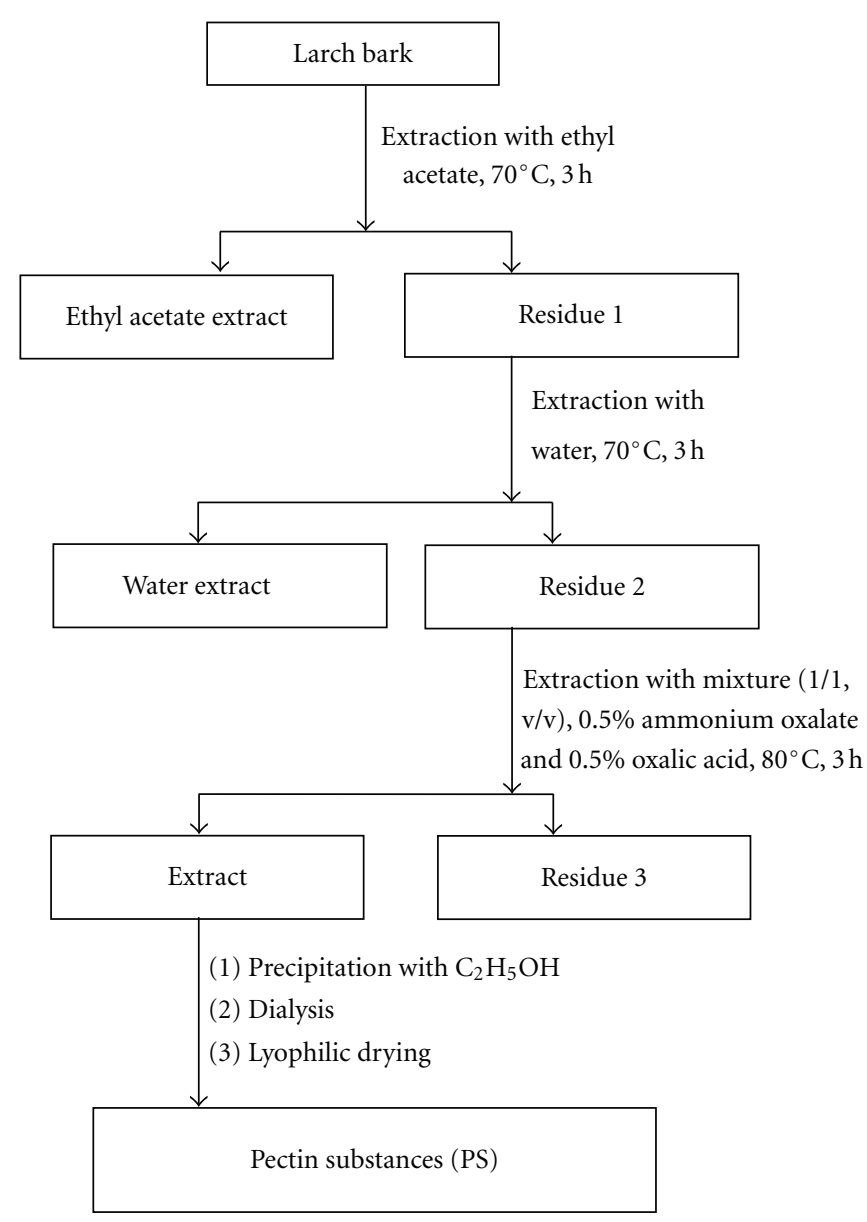

FIGURE 1: Scheme of pectin substances extraction from larch bark.

It has been established and patented that the larch bark pectin can possess reducing and stabilizing properties in the formation of nanobiocomposites with precious metals ions.

The present work aims at the following.

(1) The study of general characteristics of pectin substances (PS) extracted from bark of $L$. sibirica Ledeb. and structure investigation of its main linear and side chains.

(2) The study of PS interaction with silver nitrate and elucidation of alteration of pectin structural characteristics during the formation of "pectin- $\operatorname{Ag}(0)$ " nanobiocomposite.

\section{Methods and Materials}

Pectin substances were extracted from the bark of $L$. sibirica Ledeb. according to the scheme depicted in Figure 1. Larch air-dried bark $(500 \mathrm{~g})$ which was preliminary grinded and treated with ethyl acetate was extracted with distilled water at $70^{\circ} \mathrm{C}$ for $3 \mathrm{~h}$. The residue of raw material was poured into a mixture $(1: 1, v / v) 0.5 \%$ aqueous solution of ammonium oxalate and $0.5 \%$ aqueous solution of oxalic acid and heated at $80^{\circ} \mathrm{C}$ for $2 \mathrm{~h}$. The extract was concentrated.
Polysaccharides were precipitated with triple volume of ethyl alcohol or acetone and dried with lyophilization. As a result, PS was obtained.

PS $(50 \mathrm{mg})$ was dissolved in $20 \mathrm{~mL}$ of water. Pektinaza ( $2 \mathrm{mg}$, Sigma, USA) aqueous solution was added. The mixture was temperature-controlled at $37^{\circ} \mathrm{C}$ for $3 \mathrm{~h}$. Then, a reaction mixture was heated for $5 \mathrm{~min}$ in water bath at $100^{\circ} \mathrm{C}$. Coagulated protein was separated by centrifugation. Obtained supernatant was concentrated up to $5 \mathrm{~mL}, 96 \%$ ethyl alcohol was added (4 volumes). Deposition was separated by centrifugation. Alcoholic supernatant was concentrated and analyzed by paper chromatography (PC).

Paper chromatography was carried out on "Filtrak FN13 " paper with a descending method in n-butanol-pyridinewater system (volume correlations $6: 4: 3$, resp.). To define carbohydrates, the paper was poured with aniline phthalate and heated at $105^{\circ} \mathrm{C}$.

Glucuronic acids content in PS was defined according to the reaction with 3,5-dimethyl phenol in the presence of concentrated $\mathrm{H}_{2} \mathrm{SO}_{4}$, protein using Lowry method [1] with the calibrating schedule for a bovine serum albumin $80000 \mathrm{Da}$.

Gas-liquid chromatography (GLC) was carried out on a Hewlett-Packard 4890A (the USA) chromatograph equipped 
with flame-ionization detector, RTX-1 $(0.25 \mathrm{~mm} \times 30 \mathrm{~m})$ capillary column, argon carrier gas, $1: 60$ dumping. Temperature rate: $175^{\circ} \mathrm{C}(1 \mathrm{~min})-250^{\circ} \mathrm{C}(2 \mathrm{~min}), \Delta 3^{\circ} / \mathrm{min}$.

Total acid hydrolysis PS (5 mg) was carried out with the implementation of $2 \mathrm{M}$ trifluoroacetic acid (TFA) $(2 \mathrm{~mL})$ which contained mio-inositol $(1 \mathrm{mg} / \mathrm{mL})$. The mixture in soldered ampoule was heated for $5 \mathrm{~h}$ at $100^{\circ} \mathrm{C}$, and the acid was removed by repeated dry evaporation with methanol addition.

Ion-exchange chromatography PS (100 mg) was carried out on DEAE-cellulose $(25 \times 2 \mathrm{~cm})$ column. $\mathrm{NaCl}$ solutions were used as an eluent with increasing concentration $(0.01 \mathrm{M}-1 \mathrm{M}, 60 \mathrm{~mL} / \mathrm{h}$ elution's speed, fractions' selection by $12 \mathrm{~mL}$ ). Pick correspondent fractions at the output bents were combined, dialyzed, and lyophilized. As a result, PS 1-4 fractions were obtained. Monosaccharides of each fraction after hydrolysis of PS 1-4 and acetilation were defined by GLC.

Monosaccharides acetilation: each PS 1-4 fraction was dissolved in $1 \mathrm{M}$ ammonia solution $(1 \mathrm{~mL})$ and $5 \mathrm{mg}$ of $\mathrm{NaBH}_{4}$ was added. The mixture was kept at room temperature during one day. Then, $\mathrm{NaBH}_{4}$ abundance was destroyed by adding 2-3 drops of concentrated acetic acid; $0.2 \mathrm{~mL}$ of dry pyridine and acetic anhydride were added to a dry residue. The mixture was being acetilized at $100^{\circ} \mathrm{C}$ during $1 \mathrm{~h}$. The solution was evaporated up to pyridine and acetic anhydride abundance removal, first adding $1 \mathrm{~mL}$ of toluene and then $1 \mathrm{~mL}$ of methanol. The obtained acetate mixture of PS 1-4 polyol fractions was dissolved in $0.2 \mathrm{~mL}$ of dry chloroform and moved quantitatively to Appendorf tubes, concentrated up to $0.1-0.2 \mathrm{~mL}$, and analyzed with GLC method.

PS (5 mg) partial acidic hydrolysis was carried out with $0.05 \mathrm{M}$ TFA $(2 \mathrm{~mL})$ which contained mio-inositol $(1 \mathrm{mg} / \mathrm{mL})$. The mixture in soldered ampoule was heated at $100^{\circ} \mathrm{C}$ for $3 \mathrm{~h}$. The acid was removed by repeated dry evaporation with methanol addition to give PS-s.

PS (5 mg) partial acidic hydrolysis was carried out with $0.01 \mathrm{M}$ TFA $(2 \mathrm{~mL})$ which contained mio-inositol $(1 \mathrm{mg} / \mathrm{mL})$. The mixture in soldered ampoule was heated at $100^{\circ} \mathrm{C}$ for $3 \mathrm{~h}$. The acid was removed by repeated dry evaporation with methanol addition to afford PS-g.

IR spectra were registered on a FT-IR (RAM II) Brukker Vertex 70 spectrometer in pellets with $\mathrm{KBr}$.

${ }^{13} \mathrm{C}$ NMR spectra were recorded on a Bruker DRX 500 instrument (Germany) using 3-5\% carbohydrate solution in $\mathrm{D}_{2} \mathrm{O}$ at 55 and $70^{\circ} \mathrm{C}$; the internal standard was DMSO-d6.

Synthesis of PS-g1 and PS-g1 nanobiocomposites "pectin- $\operatorname{Ag}(0)$ " was carried out according to the [2]. To $2 \mathrm{~mL}$ of the aqueous solution containing $1 \mathrm{~g}$ pectin, added $2 \mathrm{~mL}$ of $0.12-5.92 \mathrm{mmol}$ silver nitrate solution and kept at room temperature for $30 \mathrm{~min}$, added $10 \%$ sodium hydroxide solution up to $\mathrm{pH} 11$, boiled on a water bath of $15 \mathrm{~min}$ and filtered through the paper filter. Obtained products were purified from low-molecular impurity by reprecipitations from ethanol, dried in vacuum over $\mathrm{CaCl}_{2}$. The silver content in nanobiocomposites was determined titrimetrically with ammonium thiocyanate after preliminary metal translation in the ionic form by treatment with nitric acid by [3].
UV-Vis spectra of nanobiocomposite aqueous water solutions were recorded on a Perkin Elmer Lambda 35 instrument in ultraviolet and visible areas.

\section{Results and Discussions}

Pectin substances are abundant in land and water plants, as well as some freshwater algae [6]. Being an important component of cell walls, they are involved in ion exchange, water metabolism, and cell wall structure formation. They stimulate seed germination and germ growth, provide turgor, and so forth.

Unique physicochemical properties of pectin make it indispensable material in medical, food, and cosmetic industries as gelling agent, thickener, stabilizer, and dietary fiber. Since recently, it is extensively used as a matrix carrier for biologically active components in drugs. Pectins exert diverse physiological activities such as immunomodulating, hepatoprotective, anticarcinogenic, and antimetastatic, that allow them to be applied as drugs and biologically active food additives.

The pectins are typically isolated from economically valuable pants, for example, citrus, apple, sugar beet, and sunflower head pith. Other plants such as amaranth, small mallow, duckweed, SILENE, and coffee beans, have been reported as potential sources of pectins [7-10].

The methods for isolation of pectin polysaccharides from plant tissues are numerous. Among the classic ones is hydrolysis extraction of dry raw material particles of certain sizes [11] with hot water, organic and inorganic acid solutions as well as salts, alkali or their mixtures as extracting solutions. Basic parameters of the pectin isolation process such as a raw material preprocessing, hydromodulus, temperature, extraction duration, medium $\mathrm{pH}$ and precipitator can be varied depending on characteristics of the raw material [12].

\subsection{Isolation and Structural Study of Main and Side Chains} of PS. Pectin substances were extracted from the bark of $L$. sibirica Ledeb. according to the scheme depicted in Figure 1. Pectinase treatment of a PS sample, isolated from larch bark by the above method and further analysis of the hydrolysis products by paper chromatography (PC), has shown that significant destruction of PS occurs to form free $\mathrm{D}$-galacturonic acid. High positive value of the rotation angle $\left(+245.3^{\circ}, c 0.1, \mathrm{H}_{2} \mathrm{O}\right)$ indicates $\alpha$-D-configuration of $\mathrm{D}$ galactopyranosyluronic acid residues.

Table 1 shows main maxima of the absorption bands in the IR spectra of PS and their assignment proving PS pectin nature of the samples [13]. Thus, enzyme hydrolysis and IR spectroscopy data prove that the polysaccharide isolated from larch bark refers to pectin group.

To determine the sugar composition of PS the total acid hydrolysis has been carried out. Monosaccharide identification in hydrolysate has been performed by gas-liquid chromatography. It has been shown that the sample consists of galacturonic acid and monosaccharides of arabinose, galactose, rhamnose, glucose, mannose, and (in minor quantity) xylose (Table 2). Dominating monosaccharides are galactose and arabinose in a ratio of $2.7: 1$. 
TABLE 1: Absorption band maximums in IR spectra of PS and their assignment.

\begin{tabular}{ll}
\hline Frequency $\left(\nu, \mathrm{cm}^{-1}\right)$ & Assignment \\
\hline 3460 & $\nu(\mathrm{OH}), \nu\left(\mathrm{H}_{2} \mathrm{O}\right)$ \\
3260 & $\nu(\mathrm{NH})$ \\
2962,2872 & $\nu\left(\mathrm{CH}_{3}\right)$ \\
2573 & $\nu(\mathrm{OH})$, \\
1730 & $\nu(\mathrm{C}=\mathrm{O})_{\mathrm{B}} \mathrm{COOH}$ \\
1640 & $\delta(\mathrm{OH})_{\lambda}$ \\
1540 & $\delta(\mathrm{NH})$ \\
$1380-1450$ & $\delta\left(\mathrm{C}-\mathrm{CH} \mathrm{H}_{3}\right), v(\mathrm{C}-\mathrm{O})$ pyranose rings \\
1331 & $\delta(\mathrm{OH})$ in pyranose rings \\
1265 & $\nu(\mathrm{C}-\mathrm{O})$ in esters \\
1150 & $\nu(\mathrm{C}-\mathrm{O}-\mathrm{C})$ \\
1095 & $\nu(\mathrm{C}-\mathrm{C})$ \\
1027 & $\nu(\mathrm{C}-\mathrm{OH})$ \\
890 & $\delta(\mathrm{C} 1-\mathrm{H})$ in glucopyranose ring \\
$766,629,528$ & Pulse vibrations of pyranose ring \\
\hline
\end{tabular}

Partial acid hydrolysis of PS by $0.05 \mathrm{M}$ TFA gives polysaccharide PS-s representing a linear polysaccharide with insignificant amount of side chain subunits. It is also confirmed by the decrease of the relative content of neutral monosaccharides of PS-s in comparison with their content in initial polysaccharide PS (GLC analysis of polyols peracetates of the corresponding sugars in the studied substances, Table 2) and increase of galacturonic acid content from $38.4 \%$ in PS up to $88 \%$ in PS-s.

Values of chemical shifts (CSs) of carbon atoms in ${ }^{13} \mathrm{C}$ NMR spectrum of PS-s (Table 3 ) as compared to data $[4,5]$ correspond to those of carbon atoms in D-galacturonic acid residues in pyranose constituting linear fragment of the pectin molecule (pectin core).

The signal of anomeric carbon atom at $101.9 \mathrm{ppm}$ indicates both the $(1 \rightarrow 4)$-bonding between $\mathrm{D}$-galacturonic acid residues and $\alpha$-configuration of C-1 anomeric atom. Signal at $176.2 \mathrm{ppm}$ is assigned to C-6 atom and points to the free carboxyl group in D-galacturonic acid residue. Besides, galacturonic acid residues esterified by methoxyl are present the PS-s molecule that follows from signals with CS at $172.2 \mathrm{ppm}\left(\underline{\mathrm{C}}-6-\mathrm{OCH}_{3}\right)$ and $54.4 \mathrm{ppm}\left(-\mathrm{OCH}_{3}\right)$. Ratio of integrated signal intensities of carbon atoms in the methoxyl and carboxyl groups is indicative of high degree of galacturonan methoxylation.

Ion exchange column chromatography of PS on DEAE cellulose by $0.01-0.2 \mathrm{M}$ sodium chloride aqueous solutions has yielded four polysaccharide fractions, PS 1-4, whose chemical characteristics are summarized in Table 4.

In the fractions PS-1 and PS-2, galactose and arabinose are predominant (18.26/52.96\% and $11.65 / 30.83 \%$, resp.), thus, they belong to acidic arabinogalactans. Acidic character of PS is caused bythe presence of D-galacturonic acid residues, the content of which in PS- 1 is 5 times less than in PS-2, while in PS-3 and PS-4 it is a major monosaccharide that allows PS to pectins to be assigned. Content of neutral

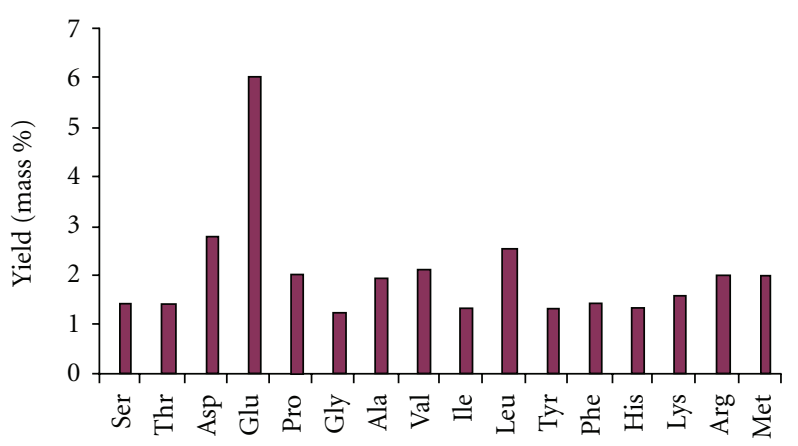

Figure 2: Amino acid composition of PS proteins.

monosaccharides in PS-4 is minimum as compared to other fractions (3 mass \%).

All the fractions contain protein substances that are not eliminated by gel filtration (Table 4). Probably, the protein and polysaccharide compounds are strongly associated, or their molecular weights are close to each other.

Amino-acid composition of PS proteins has been studied. Major components of proteins are glutamic acid (6\%) and aspartic acid (2.8\%), while total content of amino acids with aliphatic side chains (glycine, alanine, valine, isoleucine, leucine) is $9 \%$ (Figure 2).

As mentioned above, full acid hydrolysis of PS with $2 \mathrm{M}$ TFA has delivered galacturonan (PS-s). A milder treatment of PS with 0,01 M TFA gives PS-g.

According to the ${ }^{13} \mathrm{C}$ NMR data, PS-g is a pectin polysaccharide. The spectrum contains typical signals of galacturonic acid residues, namely, pronounced signals of anomeric carbon atoms at 100.4 and $100.9 \mathrm{ppm}$, and signals of the carboxyl carbon atoms at 171.4, 166.5, and $53.7 \mathrm{ppm}$, the latter two being of carbon atoms in uronic acid residues methoxylated by C-2 and C-3 atoms (Table 5). Intensities and spectral positions of signals at 68.9, 70.8, 78.9, and $72.2 \mathrm{ppm}$ correspond to literature data for $\alpha-\mathrm{D}-\mathrm{Gal}_{\mathrm{p}} \mathrm{A}$ residues connected by $1 \rightarrow 4$ bonds. A ratio of integral signal intensities of the carboxyl and methoxyl carbon atoms is $1: 5$ which testifies higher methoxylation degree of PS.

In the ${ }^{13} \mathrm{C} N M R$ spectrum of PS-g sample there were upfield signals at 17.9 and 18.13 ppm belonging to C-6 atoms in terminal rhamnose residues and in polysaccharide chains, respectively. The integral intensities of these signals and those of C-2 and/or C-3 and C-6 carbon atoms for galacturonan residues at 166.42 and $171.33 \mathrm{ppm}$ were found to have a ratio of $1: 5$. The total integral intensity of signals for anomeric C1 atoms for rhamnose and total integral intensity of signals of anomeric atoms of $s$ were equal to each other, that is, they had the same ratio for rhamnose galacturonan residue in the chain. According to data [14], signals at 99.7, 77.6, 70.8, 82.5, 68.9, and $17.9 \mathrm{ppm}$ are assigned to C-1, C-2, C-3, C-4, C-5, and $\mathrm{CH}_{3}$ carbon atoms in $\left.\rightarrow 2,4\right)-\alpha$-L-Rha $-(1 \rightarrow$ residues.

Thus, according to the ${ }^{13} \mathrm{C}$ NMR spectral data, linear fragment of pectin polysaccharide PS-g is rhamnogalacturonan (RG-I), where D-galacturonic acid residues in pyranose form with $\alpha$-configuration of anomeric center are linked by $1 \rightarrow 4$-bonds. One-fifth of galacturonan residues at C-6 atom 
TABLE 2: Monosaccharide compositions determined by GLC analysis of PS and PS-s samples.

\begin{tabular}{lccccccc}
\hline Sample & & \multicolumn{3}{c}{ Content, $\%$} & Man & Glc \\
& Gal A & Rha & Ara & Xyl & Gal \\
\hline PS & 38.4 & 1.6 & 6.8 & traces & 2.5 & 3.7 \\
PS-s & 87.86 & 0.97 & 2.75 & traces & 0.73 & 0.82 \\
\hline
\end{tabular}

TABLE 3: Chemical shifts values of carbon atoms in D-galacturonic acid residues in the ${ }^{13} \mathrm{C}$ NMR spectrum of PS-s $\left(\delta\right.$, ppm, $\left.\mathrm{D}_{2} \mathrm{O}\right)$ and of $[4,5]$.

\begin{tabular}{lcccccccc}
\hline Residue & $\mathrm{C}-1$ & $\mathrm{C}-2$ & $\mathrm{C}-3$ & $\mathrm{C}-4$ & $\mathrm{C}-5$ & $\mathrm{C}-6$ & $\mathrm{C}^{-6}-\left(\mathrm{OCH}_{3}\right)$ & $-\mathrm{OCH}{ }_{3}$ \\
\hline$\rightarrow 4)-\alpha$-D-Gal $\mathrm{p}$ - $(1 \rightarrow$ of PS-s & 101.9 & 68.9 & 72.1 & 79.2 & 73.4 & 176.2 & 172.2 & 54.4 \\
$\rightarrow 4)-\alpha$-D-Gal $\mathrm{A}-(1 \rightarrow$ of apple pectin [5] & 100.7 & 69.4 & 69.8 & 79.4 & 72.2 & 175.2 & - & - \\
$\rightarrow 4)-\beta$-D-Gal $\mathrm{A}-(1 \rightarrow[4]$ & 103.4 & 72.4 & 74.3 & 78.3 & 76.0 & 175.2 & - & - \\
\hline
\end{tabular}

TABLE 4: Chemical characterization of PS sample after DEAE-cellulose fractioning.

\begin{tabular}{|c|c|c|c|c|c|c|c|c|c|}
\hline \multirow{3}{*}{ Sample* } & \multirow{3}{*}{ Yield, \% } & \multicolumn{8}{|c|}{ Content, \% } \\
\hline & & \multirow{2}{*}{$\mathrm{Gal}_{\mathrm{p}} \mathrm{A}$} & \multirow{2}{*}{ Protein } & \multicolumn{6}{|c|}{ Monosaccharides } \\
\hline & & & & Rha & Ara & $\mathrm{Xyl}$ & Man & Glu & Gal \\
\hline PS-1 & 12.1 & 5.67 & 6.9 & traces & 18.26 & 1.54 & 2.53 & 5.95 & 52.92 \\
\hline PS-2 & 5.9 & 29.12 & 7.3 & 0.53 & 11.65 & 1.02 & 2.71 & 8.81 & 30.83 \\
\hline PS-3 & 17.0 & 65.93 & 5.7 & 1.91 & 4.45 & 0.75 & 1.18 & 1.12 & 9.42 \\
\hline PS-4 & 37.0 & 79.87 & 3.6 & 0.35 & 0.93 & 0.18 & 0.24 & 0.21 & 1.06 \\
\hline
\end{tabular}

Note: ${ }^{*}$ PS- 1 isolated with use of $0.01 \mathrm{M} \mathrm{NaCl}$ solution, PS-2—0.1 M NaCl solution, PS-3 and PS-4—0.2 M NaCl solution.

TABLE 5: Chemical shifts of carbon atom signals in ${ }^{13} \mathrm{C}$ NMR spectrum of PS-g.

\begin{tabular}{|c|c|c|c|c|c|c|c|}
\hline Residue & $\mathrm{C} 1$ & $\mathrm{C} 2$ & C3 & $\mathrm{C} 4$ & C5 & C6 & $-\mathrm{OCH}_{3}\left(\underline{\mathrm{CH}}_{3}-\right)$ \\
\hline$\rightarrow 4)-\alpha-D-G_{p} A-(1 \rightarrow$ & 100.4 & 68.9 & 70.8 & 78.9 & 72.2 & 171.4 & - \\
\hline $2-\mathrm{Me}-\alpha-\mathrm{D}-\mathrm{Gal}_{\mathrm{p}} \mathrm{A}-(1 \rightarrow$ & 100.9 & 166.5 & 69.6 & 78.9 & 73.8 & 171.4 & 53.7 \\
\hline $3-\mathrm{Me}-\alpha-\mathrm{D}-\mathrm{Gal}_{\mathrm{p}} \mathrm{A}-(1 \rightarrow$ & 100.9 & 68.9 & 166.5 & 78.9 & 73.8 & 171.4 & 53.7 \\
\hline$\rightarrow 2,4)-\alpha-\mathrm{L}-\mathrm{Rha}_{\mathrm{p}}-(1 \rightarrow$ & 99.7 & 77.6 & 70.8 & 82.5 & 68.9 & - & 17.9 \\
\hline$\beta-\mathrm{D}-\mathrm{Gal}_{\mathrm{p}}-(1 \rightarrow$ & 104.64 & 71.7 & 74.1 & 69.6 & 76.1 & 62.0 & - \\
\hline$\rightarrow 6)-\beta-D-G_{1}-(1 \rightarrow$ & 104.38 & 71.7 & 73.8 & 69.6 & 74.3 & 70.8 & - \\
\hline$\rightarrow 3,6)-\beta-\mathrm{D}-\mathrm{Gal}_{\mathrm{p}}-(1 \rightarrow$ & 104.64 & 71.7 & 82.5 & 69.57 & 74.1 & 71.4 & - \\
\hline$\alpha$-L-Ara f $^{-}(1 \rightarrow$ & 108.6 & 80.7 & 78.9 & 84.9 & 62.0 & - & - \\
\hline$\beta-\mathrm{L}-\mathrm{Ara}_{\mathrm{p}}-(1 \rightarrow$ & 101.1 & 69.6 & n.d. & n.d. & n.d. & - & \\
\hline$\rightarrow 3,5)-\alpha-\mathrm{L}-\mathrm{Ara}_{\mathrm{f}}-(1 \rightarrow$ & 108.6 & 80.7 & 84.9 & 83.2 & 67.8 & - & - \\
\hline$\rightarrow 2,5)-\alpha-\mathrm{L}-\operatorname{Ara}_{\mathrm{f}}-(1 \rightarrow$ & 108.0 & 84.9 & 77.6 & 83.2 & 67.8 & - & - \\
\hline
\end{tabular}

Note. n.d.: not determined.

is esterified by methoxy groups. The ratio between 2,4substituted rhamnopyranosyl and galacturonosyl residues $(1: 5)$ indicates that the main chain structure of the pectin polysaccharide is highly branched at C-4 atoms of rhamnopyranosyl residues.

Further ${ }^{13} \mathrm{C}$ NMR studies of PS-g sample shows that arabinogalactan subunits are present in rhamnogalacturonan as side chains. In the ${ }^{13} \mathrm{C}$ NMR spectrum of PS-g sample, in the region of anomeric carbon signals, apart from the signals of anomeric carbons in galacturonopyranosyl residues of the galactan core, appear the signals at 101.1, 104.38, 104.64, and $108.6 \mathrm{ppm}$. According to [15], intensities and values of CS can be assigned to signals of anomeric carbon atoms in $\beta$ $\mathrm{L}-\mathrm{Ara}_{\mathrm{p}}, \alpha-\mathrm{L}-\mathrm{Ara}_{\mathrm{f}}$, and $\beta-\mathrm{D}-\mathrm{Gal}_{\mathrm{p}}$ residues. The most upfield signal $(\delta 101.1 \mathrm{ppm})$ is attributable to terminal $\beta$-L-Ara residues. Signals at 104.38 and $104.64 \mathrm{ppm}$ belong to $\mathrm{C}-1$ in $\beta-\mathrm{D}-\mathrm{Gal}_{\mathrm{p}}$ residues while CS values of C-2, C-3, C-4, C-5, and $\mathrm{C}-6$ atom signals have been determined by the comparison with literature data for $\beta$-D-galactopyranosyl residues. Bonding at C-3 and C- 6 positions of $\beta$-D-galactopyranose is proved by downfield shifts of these signals by 8.7 and $8.8-$ $9.4 \mathrm{ppm}$, respectively, due to glycosylation of these atoms as compared to their positions in nonsubstituted $1 \rightarrow 3,6$ bonded $\beta-\mathrm{D}-\mathrm{Gal}_{\mathrm{p}}$ residues. Signals at $08.6 \mathrm{ppm}$, like those at $80.7,78.9,84.9$, and $62.0 \mathrm{ppm}$, are assigned to terminal $\alpha$-L-arabinofuranose. According to signal intensities of anomeric atoms of arabinose and galactose, a ratio of these monosacharides is $1: 2$. 
Hence, according to spectral data for PS-g fragment of the pectin polysaccharide from larch bark, highly branched arabinogalactan is detected as side chains consisting of linear chains with $\rightarrow 3,6)-\beta$-D-Gal $-(1 \rightarrow$ residues with branching at C-6 atoms. Side chains of arabinogalactan fragment contain terminal arabinose both in the pyranose and in furanose form as well as $\rightarrow 2,5)-\alpha$-L-Araf $-(1 \rightarrow$ and $\rightarrow 3,5)-\alpha$ $\mathrm{L}-\mathrm{Ara}_{\mathrm{f}}-(1 \rightarrow$ residues as intermediate fragments.

It is known that the reactivity of polysaccharide molecule is due to terminal sugars, mainly localized in side chains [16]. In addition, conformation features of the macromolecule, caused by intramolecular stabilization bonds between functional groups in side chains, are responsible for biological activity of a polysaccharide.

Arabinogalactan is a prevailing polysaccharide of larch wood; hence, its presence in the polysaccharides bark is owing to biogenetic reasons. It has been reported that arabinogalactan is present in the pectin substances of cell walls of plants both as associable bonding and accompanying component [17].

3.2. Study of $A g(I)$ Redox Reaction and $A g(0)$ Nanoparticles Formation and Stabilization in Pectin Polysaccharide Matrix. Significant interest to nanosize metals is caused by their high technological potential as important magnetic materials, catalysts, nonlinear-optical medium, and biologically active agents. So, for example, it has been established that silver nanoparticles possess rare combination of valuable features, that is, unique optical properties due to surface plasmon resonance, highly developed surface, catalytic activity [18], and antimicrobial activity, which is even more expressed than in ionic silver [19].

One of the widespread approaches to the synthesis of metal nanoparticles involves the reduction reaction of metal ions in a polymeric solution. As a rule, the high-molecular compound (polysaccharide) employed in this case acts as a protective polymeric screen ensuring both the size of metal nanoparticles and stabilization of the nanobiocomposite formed [20]. Borohydrides, aluminium hydrides, aminoboranes, hypophosphites, hydroquinone, formalin, light, and radiation are used as reducing agents here [21].

Another approach to the nanocomposites synthesis is based on the nanocomposites self-organization, where the polymers play a role of reducing agent and nanostabilizing medium [22]. In this case, synergism of properties of the polymeric matrix (biological activity, hydrodynamical characteristics) and those of the metal core (optical, biological, thermophysical, electric) takes place which provides for promising performance characteristics of the nanocomposites formed. According to this approach, nanobiocomposites have been prepared using natural polysaccharides: arabinogalactan [22], galactomannan, carboxymethylcellulose, geparin [23], sea seaweed polysaccharides [24], pectin [2], and so forth.

Study of the $\operatorname{Ag}(\mathrm{I})$ redox reaction and $\operatorname{Ag}(0)$ nanoparticles formation and stabilization in pectin polysaccharide matrix was carried out depending on the reaction conditions, in particular, $\mathrm{pH}$ value, initial reagents ration (metal salt/pectin), and reaction time.
The absorption spectra of pectin and silver nitrate aqueous solutions at different reaction time are depicted in Figure 3(a). It has been found that at $\mathrm{pH} 3.5$ reduction reaction $\operatorname{Ag}(\mathrm{I})$ proceeds very slowly. It is supported by the appearance of a bond in the absorption spectrum at $\lambda 280$ $470 \mathrm{~nm}$ only $24 \mathrm{~h}$ after the reaction beginning (Figure 3(a)). Wide maximum of the low intensive bond indicates the formation of primary centers of metal silver. Besides, the reaction rate is so slow that even $96 \mathrm{~h}$ is not enough for the generation of totally recovered $\operatorname{Ag}(0)$ centers. For the reaction of pectin with $\mathrm{Ag}(\mathrm{I})$ at $\mathrm{pH}$ 7, a symmetric bond at $\lambda_{\max } 420 \mathrm{~nm}$ is observed in the electron spectra thus proving the formation of $\operatorname{Ag}(0)$ nanoparticles (Figure 3(b), line 2). Total conversion of silver cations, which is experimentally evaluated by the growth of the absorption bond intensity, is reached for about $24 \mathrm{~h}$. The reduction $\operatorname{Ag}(\mathrm{I})$ with pectin at $\mathrm{pH} 11-12$ occurs instantly just after the reagents mixing (Figure 3(b), line 4 and Figure 3(c) line 1) and is completed in $30 \mathrm{~min}$. The reduction under these conditions is also accompanied by variations of $\operatorname{Ag}(0)$ particle sizes which follows from the shift in Plasmon pick position into shortwave region by $10 \mathrm{~nm}$ (Figure 3(c), line 5).

Thus, the increase in rate of $\mathrm{Ag}(\mathrm{I})$ reduction with pectin at elevated $\mathrm{pH}$ value allows one to assume the direct participation of $\mathrm{OH}^{-}$in this reaction.

In the alkaline medium, polysaccharides are known to undergo diverse transformations [25-27] such as depolymerization, alkaline hydrolysis, and oxidizing destruction.

${ }^{13} \mathrm{C}$ NMR spectroscopy data (Tables 5 and 6 ) indicate that these processes take place during the interaction of PS with $\mathrm{Ag}(\mathrm{I})$ in the alkaline medium. The data of ${ }^{13} \mathrm{C}$ NMR spectrum of PS-g1, containing $20 \%$ of $\mathrm{Ag}(0)$, are given in Table 6.

The comparison of ${ }^{13} \mathrm{C}$ NMR spectra of PS-g1 and PS$\mathrm{g}$ has shown that PS-g1 represents a partially destructed acidic polysaccharide. This is evidenced from the presence $\left({ }^{13} \mathrm{C}\right.$ NMR $)$ of characteristic signals of anomeric carbons at $100.3 \mathrm{ppm}$ in the $\rightarrow 4)-\mathrm{D}-\mathrm{Gal}_{\mathrm{p}} \mathrm{A}-\left(1 \rightarrow\right.$ and $6-\mathrm{Me}-\alpha-\mathrm{D}-\mathrm{Gal}_{\mathrm{p}}-$ $(1 \rightarrow$ residues in rhamnogalacturonan (Table 6$)$. At the same time, the number of C- 6 substituted acid residues $(8: 1)$ as compared to their content in the starting polysaccharide $(5: 1)$ has been decreased. Also, the signals of carbon atoms in galactopyranosyl residues that have different locations in linear chain, that is, terminal $1 \rightarrow 6$ - and $1 \rightarrow 3,6$-substituted galactopyranosyl residues, have been detected in the spectrum. The values of chemical shifts of carbon atoms at 108.6, $80.7,78.9,84.9$, and $62.0 \mathrm{ppm}$ are assigned to C-1-6 atoms of terminal $\alpha$-L-Araf. RG-I region of the PS-g1 sample also undergoes destructive changes. First, its labile side chains containing highly branched arabinozil fragments involve in the alkaline hydrolysis. The fact of the destruction is also supported by the presence (in ${ }^{13} \mathrm{C}$ NMR spectra of PSg1 and PS-g samples) of signals of carbon atoms assigned to galactopyranosyl residues linked by $1 \rightarrow 3$ - and $1 \rightarrow 3,6-$ bonds. Arabinose residues in furanoside cycles are present only as terminal residues.

The structure of PS-g2 differs from that of PS-g1 by the content of $\operatorname{Ag}(0)(72 \%)$. According to ${ }^{13} \mathrm{C}$ NMR data (Table 7), carbohydrate counterpart of the former represents 


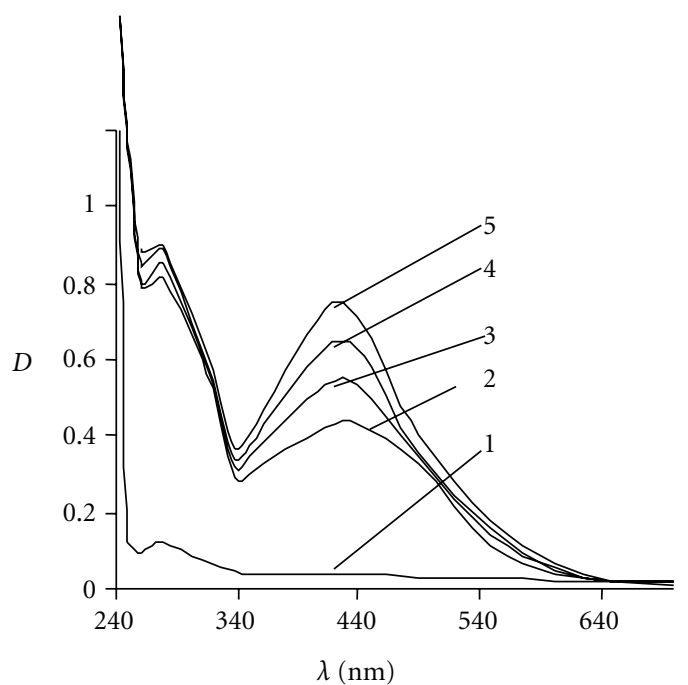

(a)

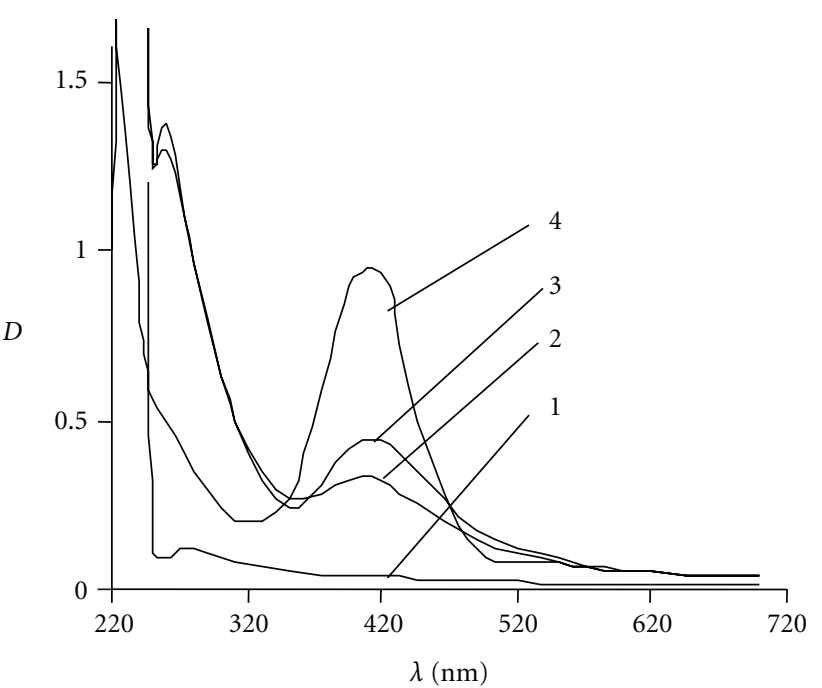

(b)

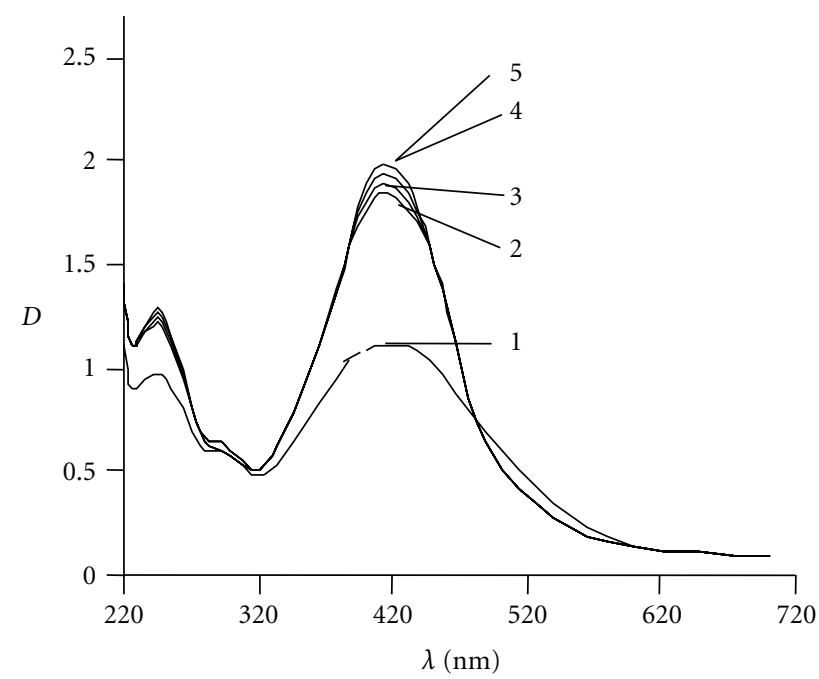

(c)

FIGURE 3: Absorption spectra of a mixture of aqueous solutions of pectin (0.5\%) and silver nitrate (0.1\%) in a ratio of $1: 1$ depending on (a)

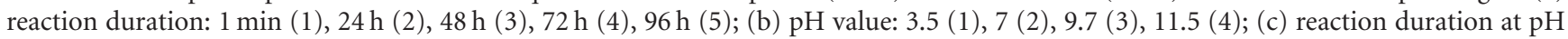
11.5: $1 \mathrm{~min}(1), 30 \mathrm{~min}(2), 60 \mathrm{~min}(3), 180 \mathrm{~min}(4), 24 \mathrm{~h}$ (5).

a product of deeper destruction of the initial polysaccharide PS-g. First of all, the signals of carbon atoms, characteristic for acid polysaccharides and its methoxylated derivatives [28], are absent in low-field region of the spectrum at 166$177 \mathrm{ppm}$. Also, the signals of carbon atoms of rhamnose residues are not observed in the spectrum. It has been established that the main structural component of PS-g2 sample is the linear fragment comprising $1 \rightarrow 3$-linked galactopyranosides residues and bearing the side fragments in the form of terminal $\beta$-L-Ara $\mathrm{p}_{\mathrm{p}}$ and $\beta$-D-Gal $\mathrm{p}_{\mathrm{p}}$ residues and/or olygosaccharides with $1 \rightarrow 3$-linked galactopyranosides residues and attached by $\beta$-L-Ara and $\beta$-D-Gal perminal residues.

Thus, the comparison of structural characteristics of the initial pectin with those of "pectin- $\mathrm{Ag}(0)$ " nanobiocomposites PS-g1 and PS-g allows one to assume that in the reaction studied the pectin polysaccharide acts a reducing agent and also undergoes destructive changes. Pectin carboxy-groups and other groups $(-\mathrm{OH},=\mathrm{O})$ are contained in structure of side chains of RG-I participate in formation of zero-valence silver participates.

The destruction of PS-g1 backbone in rhamnosyl residue is observed upon the addition of larger quantities of $\mathrm{Ag}(\mathrm{I})$ to the reaction. As a result, RG-I is abstracted, the main chain of which is less destructed by this moment and stabilizes the $\operatorname{Ag}(0)$ nanoparticles.

Efficiency of stabilization functions has been estimated by influence of quantitative ratio of the initial pectin substances taken in reaction: metal salt $(\mathrm{mmol}) /$ pectin $(1 \mathrm{~g})$ on the content of $\operatorname{Ag}(0)$ nanoparticles and their sizes in formed nanobiocomposites "pectin- $\operatorname{Ag}(0)$." It has been shown that in area $0.1-2.5 \mathrm{mmol} A g N O 3 / 1 \mathrm{~g}$ of pectin the content of zero-valent silver in received nanobiocomposite is indirectly 
TABLe 6: Chemical shifts $\left(\delta\right.$, ppm, $\left.\mathrm{D}_{2} \mathrm{O}\right)$ of carbon atom signals of the carbohydrate residues in ${ }^{13} \mathrm{C}$ NMR spectrum of PS-g1 sample.

\begin{tabular}{|c|c|c|c|c|c|c|c|}
\hline Residue & $\mathrm{C}-1$ & $\mathrm{C}-2$ & $\mathrm{C}-3$ & $\mathrm{C}-4$ & $\mathrm{C}-5$ & $\mathrm{C}-6$ & $-\mathrm{OCH}_{3}$ \\
\hline$\rightarrow 4)-\alpha-\mathrm{D}-\mathrm{Gal}_{\mathrm{p}} \mathrm{A}-(1 \rightarrow$ & 100.3 & 69.5 & 70.2 & 78.0 & 72.2 & 176.8 & \\
\hline $6-\mathrm{Me}-\alpha-\mathrm{D}-\mathrm{Gal}_{\mathrm{p}} \mathrm{A}-(1 \rightarrow$ & 100.3 & 69.5 & 70.0 & 78.0 & 74.1 & 174.7 & 55.4 \\
\hline$\rightarrow 2,4)-\alpha-\mathrm{L}-\mathrm{Rha}_{\mathrm{p}}-(1 \rightarrow$ & 99.7 & 77.6 & 71.0 & 82.5 & 72.8 & 18.0 & \\
\hline$\beta-\mathrm{D}-\mathrm{Gal}_{\mathrm{p}}-(1 \rightarrow$ & 104.7 & 71.7 & 74.1 & 69.5 & 76.6 & 62.5 & \\
\hline$\rightarrow 6)-\beta-\mathrm{D}-\mathrm{Gal}_{\mathrm{p}}-(1 \rightarrow$ & 105.1 & 71.7 & 74.1 & 69.5 & 72.7 & 70.3 & \\
\hline$\rightarrow 3,6)-\beta-\mathrm{D}-\mathrm{Gal}_{\mathrm{p}}-(1 \rightarrow$ & 105.1 & 71.7 & 82.7 & 70.1 & 72.7 & 71.7 & \\
\hline$\alpha$-L-Ara $\mathrm{f}_{\mathrm{f}}(1 \rightarrow$ & 108.6 & 80.7 & 78.9 & 84.9 & 62.0 & - & \\
\hline
\end{tabular}

TABLE 7: Chemical shifts $\left(\delta\right.$, ppm, $\left.\mathrm{D}_{2} \mathrm{O}\right)$ of carbon atoms of the carbohydrate residues in ${ }^{13} \mathrm{C}$ NMR spectrum of PS-g2 sample.

\begin{tabular}{|c|c|c|c|c|c|c|}
\hline Residue & $\mathrm{C}-1$ & $\mathrm{C}-2$ & $\mathrm{C}-3$ & $\mathrm{C}-4$ & $\mathrm{C}-5$ & C-6 \\
\hline$\beta-\mathrm{D}-\mathrm{Gal}_{\mathrm{p}}-(1 \rightarrow$ & 104.8 & 71.7 & 74.2 & 69.6 & 76.6 & 62.5 \\
\hline$\rightarrow 6)-\beta-\mathrm{D}-\mathrm{Gal}_{\mathrm{p}}-(1 \rightarrow$ & 104.8 & 71.7 & 74.2 & 69.6 & 72.8 & 70.1 \\
\hline$\rightarrow 3,6)-\beta-\mathrm{D}-\mathrm{Gal}_{\mathrm{p}}-(1 \rightarrow$ & 104.8 & 71.7 & 82.8 & 70.1 & 74.9 & 71.7 \\
\hline
\end{tabular}

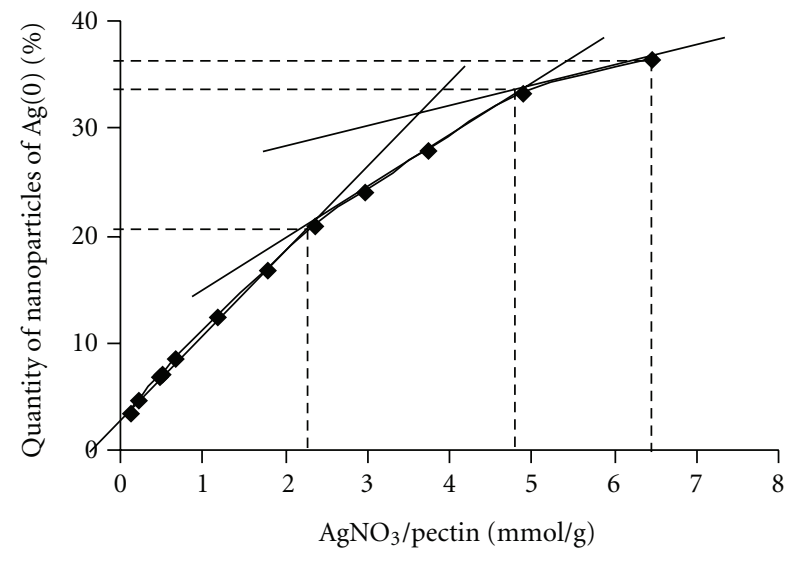

FIGURE 4: Influence of a ratio of initial metal salt/pectin on the content of $\operatorname{Ag}(0)$ in formed nanobiocomposites.

proportional relationship of quantity the salt taken in treatment (Figure 4). In these conditions the size of received silver nanoparticles, according to data electronic microscopy, is $5-7 \mathrm{~nm}$. With further increase of the initial ratio of metal salt/pectin the bends in the curve are observed, which suggests that a part of the resulting $\operatorname{Ag}(0)$ is not involved in formation nanobiocomposites. Results of the Roentgen phase analysis of this insoluble phase (Figure 5) showed that it is a metal silver with well-formed crystalline cubic structure. At a ratio of initial components from 5 up to $6.5 \mathrm{mmol}$ $\mathrm{AgNO} 3 / 1 \mathrm{~g}$ of pectin the gain of $\operatorname{Ag}(0)$ in nanosize area is not significant, and allows to receive the nanobiocomposite "pectin- $\operatorname{Ag}(0)$ " with the content of $\operatorname{Ag}(0)$ nanoparticals at $36.4 \%$ whose size is in area from 6 up to 15 nanometers.

The content of $\operatorname{Ag}(0)$ nanoparticals in nanobiocomposite "pectin- $\operatorname{Ag}(0)$ " can be increased up to $72 \%$ using the most nanobiocomposite as an initial component. It should be noted that thus the size of nanoparticals in nanobiocomposite increases and is from 4 up to $27 \mathrm{~nm}$.

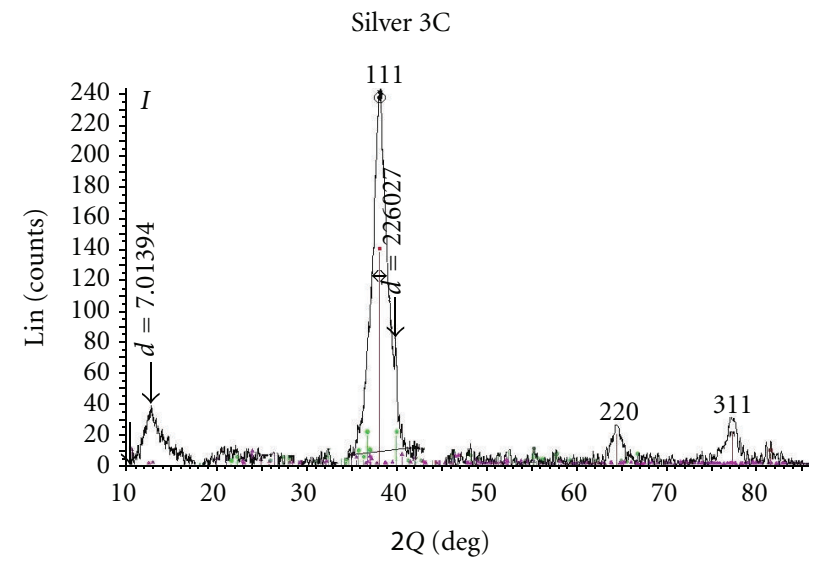

FIGURE 5: Diffractogram of precipitate formed in the reaction medium at use of initial components in area from 2.5 up to $6.5 \mathrm{mmol}$ of $\mathrm{AgNO}_{3} / 1 \mathrm{~g}$ of pectin.

\section{Conclusions}

In conclusion, the interaction of aqueous solutions of pectin with silver nitrate affords "pectin- $\operatorname{Ag}(0)$ " nanobiocomposites, where pectin plays reducing and stabilizing roles. The reaction rate essentially increases when $\mathrm{pH}$ values of the reaction mixture are close to alkaline ones. The ratio of the starting reactants influences the content of $\operatorname{Ag}(0)$ in the nanobiocomposites and their sizes: the more is $\operatorname{Ag}(\mathrm{I})$ per $1 \mathrm{~g}$ of pectin, the lower amount of $\operatorname{Ag}(0)$ nanoparticles is formed.

It has been established $\left({ }^{13} \mathrm{C} \mathrm{NMR}\right)$ that when $0.1-2.5 \mathrm{~mol}$ of $\mathrm{AgNO}_{3}$ and $1 \mathrm{~g}$ of pectin are employed in the reaction, the PS structure is preserved. The increase of $\mathrm{Ag}(\mathrm{I})$ amount up to $6.5 \mathrm{mmol}$ leads to the pectin destruction with abstracting the side fragments and destruction of rhamnogalacturonan core. Under ratio of $\mathrm{AgNO}_{3} /$ pectin equaling $6.5 \mathrm{mmol} / 1 \mathrm{~g}$, the formation of the nanocomposite is stopped due to the total destruction of pectin polysaccharide. 
Thus, in the reaction of "pectin- $\operatorname{Ag}(0)$ " nanobiocomposites formation, pectin acts as having reducing and stabilizing functions and regulates the sizes of $\operatorname{Ag}(0)$ nanoparticles.

\section{References}

[1] O. H. Lowry, N. J. Rosebrough, A. L. Farr, and R. J. Randall, "Protein measurement with the Folin phenol reagent," The Journal of Biological Chemistry, vol. 193, no. 1, pp. 265-275, 1951.

[2] V. A. Babkin, N. V. Ivanova, N. N. Trofimova et al., "Isolation of pectin, possessing membrane stabilizing activity and ability to reduce silver ions, from larch wood," Silver nanocomposites stabilized by pectin. Pat RU, 2403263, 2010.

[3] A. P. Krechkov, The Foundations of Analytic Chemistry, vol. 2, Khimya, 1978.

[4] R. G. Ovodova, O. A. Bushneva, A. S. Shashkov, A. O. Chizhov, and Y. S. Ovodov, "Structural studies on pectin from marsh cinquefoil Comarum palustre L," Biokhimiya, vol. 70, no. 8, pp. 1051-1062, 2005.

[5] P. Odonomažig, D. Balga, and A. Ebrigerova, "Structures of pectin polysaccharides isolated from the Siberian apricot (Armaniaca sibirica Lam)," Carbohydrate Research, vol. 226, pp. 353-358, 1992.

[6] Y. S. Ovodov, V. V. Golovchenko, E. A. Gunter, and S. V. Popov, Pectin Substances in Plants of European North of Russia, Uro RAN, Ekaterinburg, Russia, 2009.

[7] S. T. Minzanova, V. F. Mironov et al., "Technological aspects of receiving fodder additives from the amarant," Doklady Chemistry, vol. 3, pp. 363-366, 2007.

[8] V. N. Bubenchikov, I. L. Drozdova, and V. I. Kochkarov, Method of Isolation of the Polysaccharides Possessing AntiInflammatory Activity, Pat RU, 2002.

[9] R. G. Ovodova, S. V. Popov, O. A. Bushneva et al., "Branching of the galacturonan backbone of comaruman, a pectin from the marsh cinquefoil Comarum palustre L," Russian Journal of Bioorganic Chemistry, vol. 71, no. 5, pp. 652-671, 2006.

[10] M. K. Gelgay, L. V. Donchenko, and A. I. Reshetnyak, "Innovative technology of pectin from secondary sources of raw material after processing coffee," New Technologies, vol. 6, pp. 15-18, 2008.

[11] G. B. Aimukhomedova and N. P. Shelukhina, Pectin Substances and Their Determination Methods, Ilim, Frunze, Russia, 1964.

[12] N. V. Ivanova, O. V. Popova, and V. A. Babkin, "Analysis of influecing of the different factors on an output and some characteristics of pectin materials of a Larch bark," Khimiya Rastitel'nogo Syr'ya, no. 4, pp. 43-46, 2003.

[13] K. Nakanisi, Infrared Spectra and Structure of Organic Compounds, Moscow, Russia, 1965.

[14] R. G. Ovodova, V. V. Golovchenko, A. S. Shashkov, S. V. Popov, and Y. S. Ovodov, "Structural studies and physiological activity of lemnan, a pectin from Lemna minor L," Russian Journal of Bioorganic Chemistry, vol. 26, no. 10, pp. 669-676, 2000.

[15] S. Karacsonyi, V. Kovacik, J. Alfoldi et al., "Chemical and 13Cn.m.r. studies of an arabinogalactan from Larix sibirica L," Carbohydrate Research, vol. 134, no. 2, pp. 265-274, 1984.

[16] S. D. Achubaeva, Chemical Reactions of Pectinaceous Substances, Ilim, Frunze, Russia, 1984.

[17] A. E. Clarke, R. L. Anderson, and B. A. Stone, "Form and function of arabinogalactans and arabinogalactan-proteins," Phytochemistry, vol. 18, no. 4, pp. 521-540, 1979.

[18] Y. A. Krutyakov, A. A. Kudrinskiy, A. Y. Olenin, and G. V. Lisichkin, "Synthesis and properties of silver nanoparticles: advances and prospects," Russian Chemical Reviews, vol. 77, no. 3, pp. 233-257, 2008.

[19] A. A. Kornevskii, V. V. Sorokin, and G. I. Karavaiko, "Cooperating of silver ions with the cages of Canlida utilis," Microbiologia, vol. 6, pp. 1085-1092, 1993.

[20] O. E. Litmanovich, "Psevdomatrix sintez of polimer-metal nanocomposite sols: interakion of macromolecules with metal nanoparticles," Chinese Journal of Polymer Science C, vol. 58, no. 7, pp. 1370-1396, 2008.

[21] A. D. Pomogailo, "Polymer-immobilised nanoscale and cluster metal particles," Uspekhi Khimii, vol. 66, no. 8, pp. 785-791, 1997.

[22] B. A. Trofimov, B. G. Sukhov, G. P. Aleksandrova et al., "Nanocomposites with magnetic, optical, catalytic, and biologically active properties based on arabinogalactan," Doklady Chemistry, vol. 393, no. 4-6, pp. 287-288, 2003.

[23] B. A. Trofimov, B. G. Sukhov, G. P. Aleksandrova et al., "Polyfunctional self-organized hybrid nanobiocomposetes on basis of natural polymers," http://edu-cons.net/atlas_last/doc/302/ 1(2).pdf.

[24] I. N. Yurkova, D. A. Panov, and V. A. Ryabushko, "Study of optical properties of nanobiocomposites on silver and marine alga polysaccharides base," Uchenye Zapiski Tavricheskogo Universiteta Series Biologiya and Khimiya, vol. 22, no. 1, pp. 203207, 2009.

[25] O. P. Golova and N. V. Nosova, "Oxidative-alkaline destruction of cellulose," Russian Chemical Reviews, vol. 42, no. 4, pp. 743-767, 1973.

[26] P. A. Gachonidze, "Saccharine acids," Russian Chemical Reviews, vol. 49, no. 4, pp. 743-767, 1980.

[27] B. P. Nikolskii, Novyi Spravochnik Chimika I Technologa, 2009.

[28] I. V. Norgov, Progress in Carbohydrate Chemistry, Nauka, Moscow, Russia, 1985. 


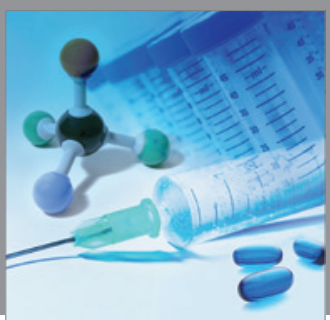

International Journal of

Medicinal Chemistry

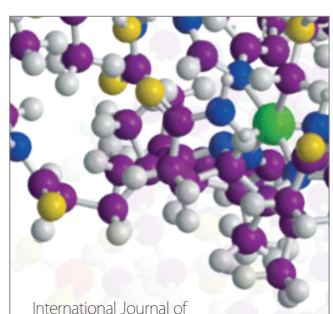

Carbohydrate Chemistry

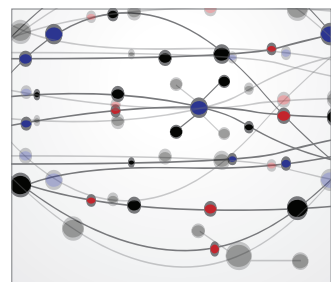

The Scientific World Journal
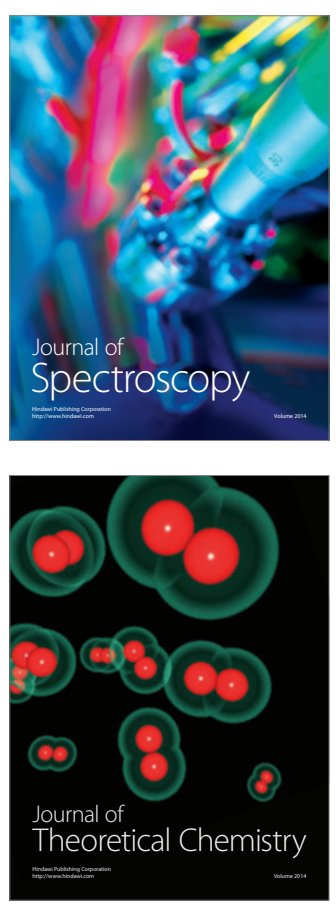
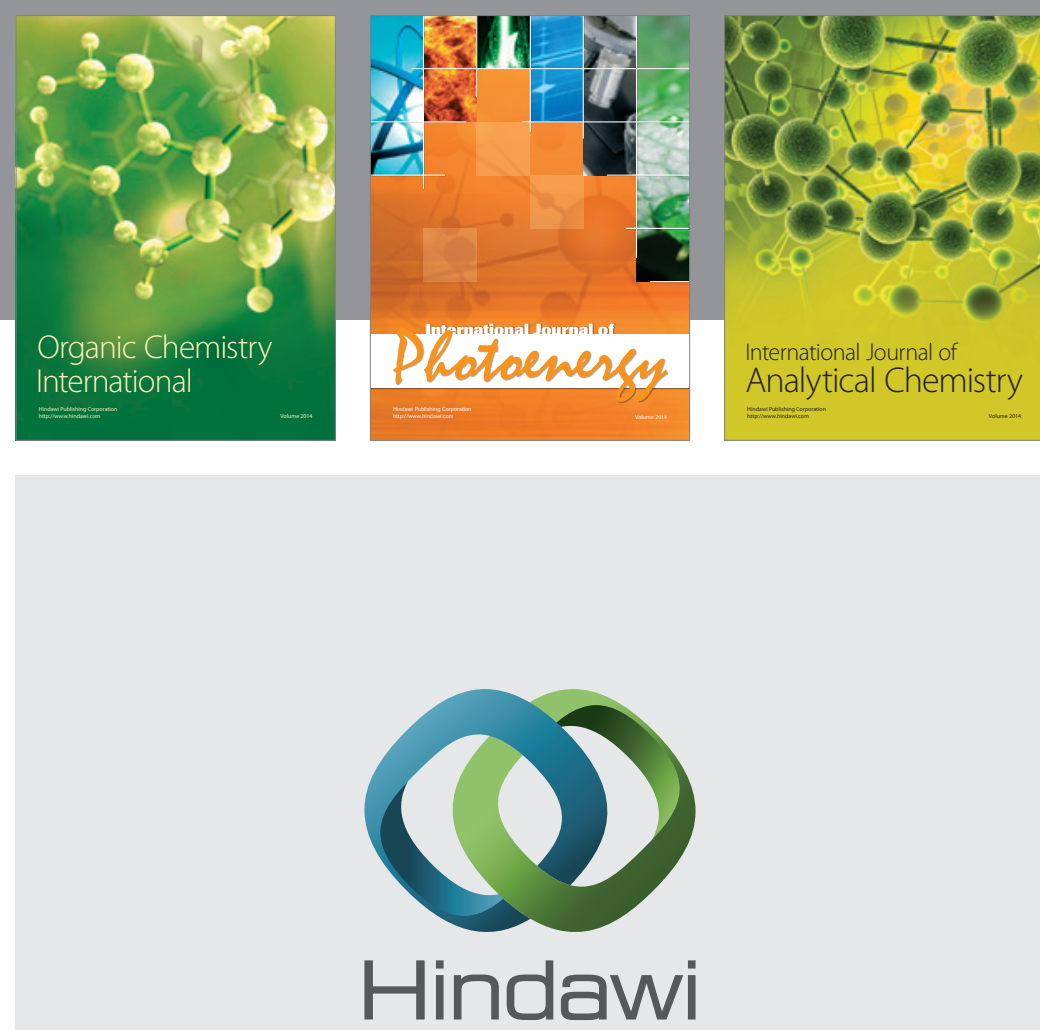

Submit your manuscripts at

http://www.hindawi.com
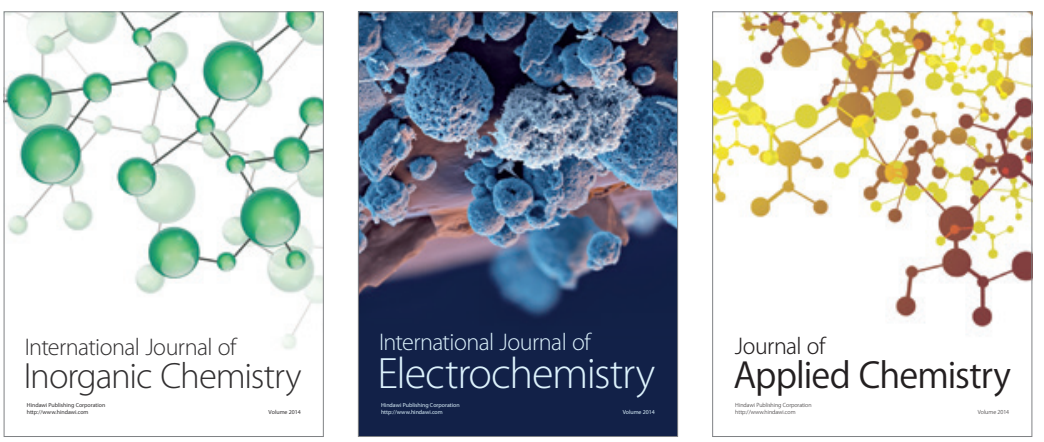

Journal of

Applied Chemistry
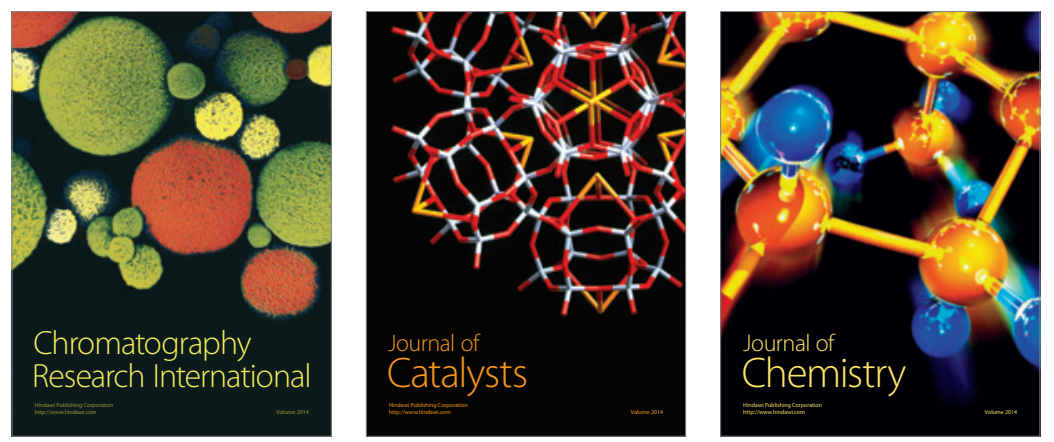
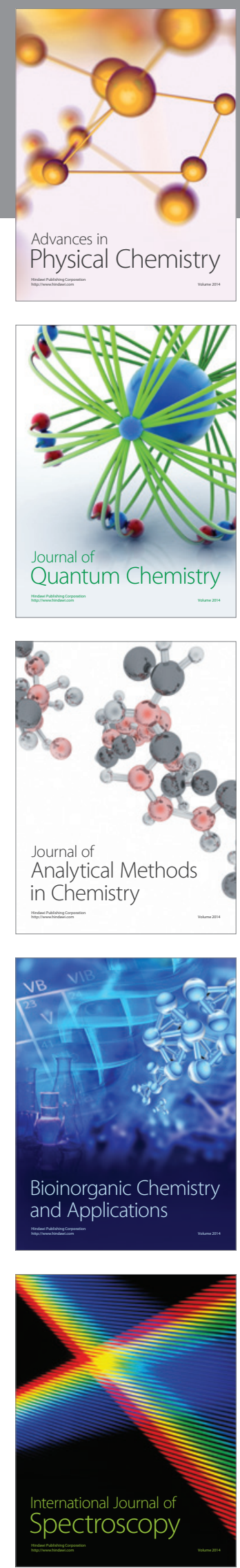